\title{
Religion's Role in Promoting Health and Reducing Risk Among American Youth
}

\author{
John M. Wallace Jr., PhD \\ Tyrone A. Forman, MA
}

\begin{abstract}
Although past research has long documented religion's salutary impact on adult health-related behaviors and outcomes, relatively little research has examined the relationship between religion and adolescent health. This study uses large, nationally representative samples of high school seniors to examine the relationship between religion and behavioral predictors of adolescent morbidity and mortality. Relative to their peers, religious youth are less likely to engage in behaviors that compromise their health (e.g., carrying weapons, getting into fights, drinking and driving) and are more likely to behave in ways that enhance their health (e.g., proper nutrition, exercise, and rest). Multivariate analyses suggest that these relationships persist even after controlling for demographic factors, and trend analyses reveal that they have existed over time. Particularly important is the finding that religious seniors have been relatively unaffected by past and recent increases in marijuana use.
\end{abstract}

Historically, infectious diseases were the leading causes of sickness and death among Americans; today, however, Americans' morbidity and mortality result largely from social, environmental, and behavioral causes. ${ }^{1}$ Recognizing the shift from biomedical to psychosocial causes of sickness and death, researchers have increasingly sought to identify psychosocial factors that protect health. In their search, researchers have discovered that religion, in its social, environmental, and behavioral forms, appears to have a salutary impact on health. ${ }^{2-4}$ In fact, systematic reviews of the research literature reveal more than 300 studies that document a positive association between religion and physical health-effects that have been found over time and across sociodemographic groups (e.g., gender, race/ethnicity, social class). ${ }^{2.5}$

Adolescents are an important sociodemographic group that is surprisingly absent from the growing body of research on the relationship between religion and health. ${ }^{6}$ Indicative

John M. Wallace Jr. is an assistant professor in the School of Social Work, an adjunct professor in the Department of Sociology, and a faculty associate at the Institute of Social Research, University of Michigan, Ann Arbor. Tyrone A. Forman is a doctoral student in the Department of Sociology at the University of Michigan, Ann Arbor.

Address reprint requests to John M. Wallace Jr., University of Michigan, Institute for Social Research, 426 Thompson Street, Ann Arbor, MI 48106-1248; phone: (313) 763-5043; fax: (313) 936-0043; e-mail: johnwall@umich.edu

This study was funded by research grant number R29DA09106 from the National Institute on Drug Abuse Health (NIDA) to the first author and grant number R24MH51363 from the National Institute on Mental Health (NIMH) and an NIDA training fellowship to the second author. The opinions expressed herein are those of the authors and not those of the funders. The authors would like to thank Deborah Willis for comments on an earlier version of this article and assistance with manuscript preparation. The authors also wish to thank two anonymous reviewers for their helpful comments on an earlier draft. 
of the paucity of research on religion and adolescent health is the fact that one of the largest and perhaps most important summaries of research on adolescent health to date-the U.S. Congress' 726-page report, Adolescent Health ${ }^{7}$-included only two references to religion. The first simply mentioned the importance of churches and synagogues as places to offer activities to adolescents, and the second noted that there is a negative relationship between "religiousness" and initiation into sexual activity. Similarly, the recently published Handbook of Adolescent Health Risk Behavior ${ }^{8}$ includes only two references to religion: The first indicates that religion may be protective against black and Hispanic youth suicide, and the second notes that the Catholic Church sponsors the largest agencies serving homeless youth. ${ }^{8}$

Although some researchers ${ }^{9,10}$ have identified "lack of religiosity" or "low religiousness" as a risk factor for a number of different problem behaviors, religion measures are not routinely included in research, and research that explicitly examines religion and health among young people is relatively rare. ${ }^{6}$ Where this research does exist, it typically conceptualizes religion as a "social control" against so-called delinquent or deviant behavior, with relatively little attention given to the potential health preventive, ${ }^{11}$ promotive, or enhancing aspects of religion identified in the adult literature. ${ }^{12-14}$ Often, when religion measures are included in research, their relationship to health-related outcomes is ignored or minimized. For example, a widely cited review of risk and protective factors for adolescent drug abuse "hides" religion under the subheading of "alienation and rebellion," noting that alienation, low religiosity, and rebelliousness relate positively to drug use and delinquency. ${ }^{9}$

The explanation for researchers' apparent lack of interest in the relationship between religion and adolescent health issues, beyond delinquency, is unclear. Whatever the explanation, however, the lack of research on religion and adolescent health is surprising given (1) a large and growing body of research on the relationship between religion and health among adults and (2) empirical evidence that many causes of adult sickness and death directly result from behavior patterns initiated during adolescence. ${ }^{1}$

The current research seeks to extend the scientific knowledge base on the relationship between religion and adolescent health. Toward this end, this article first reviews key risk factors for adolescent morbidity and mortality. It then discusses the epidemiology of religion among American youth, describes the conceptual framework that guides the investigation, and examines empirically the relationship between religion and a range of health behaviors that can both compromise and enhance adolescent health.

\section{BEHAVIORAL CAUSES OF ADOLESCENT MORBIDITY AND MORTALITY}

Like adults, the primary threats to adolescent health are no longer biomedical in origin; their source is social, environmental, and behavioral. These so-called social morbidities can be grouped into six general categories: behaviors that result in unintentional and intentional injury, alcohol and other drug use, sexual activity, tobacco use, dietary patterns, and physical inactivity. ${ }^{1,15}$ Injury is the number one cause of death among American youth and a significant cause of adolescent morbidity. Unintentional injuries account for more than $60 \%$ of all injury deaths among American teenagers. ${ }^{16}$ Leading causes of unintentional injury include motor vehicle accidents, drowning, firearms, poisons, and fires. ${ }^{17}$ Nationally, $78 \%$ of unintentional injuries among young people are attributable to motor vehicle accidents. ${ }^{18}$ Behaviors that increase an adolescent's risk for automobile injury and 
death include failure to use seat belts, driving a car under the influence of alcohol or other drugs, or riding in a car when the driver has been drinking or using other drugs. According to the Center for Disease Control and Prevention's 1995 Youth Risk Behavior Surveillance Survey (YRBSS), ${ }^{15} 22 \%$ of American young people rarely or never use seat belts, and $39 \%$ indicate that, within the past month, they had ridden with someone who had been drinking alcohol. ${ }^{15}$

Intentional injuries-specifically homicide and suicide-are the second and third leading causes of death among adolescents, respectively. ${ }^{17}$ Firearms account for the majority of homicide and suicide deaths. In 1990, for example, there were more than 9,400 firearm deaths among youth in America; $60 \%$ were homicides, $33 \%$ were suicides, $5 \%$ were unintentional injuries, and $1 \%$ were undetermined ${ }^{17}$ In 1991 , there were more than 4,700 suicides among American youth. ${ }^{17}$ Key behavioral risk factors for intentional injury mortality include carrying firearms and other weapons, fighting, and attempting suicide. According to the YRBSS, $20 \%$ of youth had carried a weapon during the past month, $39 \%$ had been in a physical fight during the past year, and $9 \%$ had attempted suicide within the past year.

Tobacco use is America's greatest preventable cause of morbidity and mortality. In fact, each of the three leading causes of death among adults-heart disease, cancer, and stroke - are related to tobacco use, a behavior that $82 \%$ of adult daily smokers initiated before they were age $18 .{ }^{19}$ Nationally, $71 \%$ of youth report that they have ever smoked cigarettes, $35 \%$ indicate that they have smoked cigarettes during the past month, $16 \%$ say that they smoked cigarettes on 20 or more days during the past month, and $11 \%$ used smokeless tobacco during the past month. ${ }^{15}$

Alcohol and other drug use are also important health behaviors that are related to adult and adolescent sickness and death. Among adults, alcohol and illicit drugs are responsible for approximately 120,000 lives each year. ${ }^{1}$ As noted above, alcohol and other drug use are key predictors of the leading cause of adolescent mortality-motor vehicle injuries - as well as other injuries and illnesses. Nationally, adolescent use of alcohol is widespread, and there is evidence that the use of illicit drugs, particularly marijuana, is on the rise. ${ }^{20}$ Data from the YRBSS indicate that half $(52 \%)$ of American adolescents drank during the past month, a third (33\%) participated in episodic heavy drinking during the past month, a quarter (25\%) used marijuana during the past month, $2 \%$ ever injected illegal drugs, and $20 \%$ ever inhaled intoxicating substances. ${ }^{15}$

Precocious adolescent sexual activity potentially has serious implications for adolescent and adult health. The health consequences of adolescent sexual involvement include increased risk for pregnancy, sexually transmitted diseases (including HIV), and other maladies such as cancers of the cervix and uterus. ${ }^{1,21}$ Among high school students, 53\% report ever having had sexual intercourse, $18 \%$ report having had four or more sexual partners, and 38\% report having sexual intercourse during the past 3 months. ${ }^{15}$ Among adolescents who are sexually active, the percentages not using a condom (46\%) and not using birth control pills ( $83 \%$ ) during their most recent intercourse experience are high. ${ }^{15}$

Dietary and physical activity patterns developed during adolescence often persist into adulthood and, in turn, significantly affect adult mortality and morbidity. In fact, second only to tobacco use, diet and physical activity patterns are the leading cause of death among adults, accounting for an estimated 300,000 deaths annually. Regarding dietary behaviors among youth, $72 \%$ of high school students in the YRBSS ate less than the recommended five servings of fruits and vegetables the day before the survey, $39 \%$ ate more than two servings of high-fat food, $28 \%$ thought they were overweight, and $41 \%$ were attempting to lose weight. ${ }^{15}$ In addition to having relatively poor diets, the level of physi- 
cal activity among American youth is also relatively low. For example, more than onethird (36\%) participated in vigorous physical activity less than 3 days in the past week, $79 \%$ participated less than 5 days in the past week, $40 \%$ were not enrolled in physical education classes, and $75 \%$ did not attend physical education class daily. ${ }^{15}$

In sum, adolescent health behaviors are key predictors of adolescent and adult mortality and morbidity. Nationally, many young people engage in behaviors that can compromise their physical well-being and that may, in the long run, prove deleterious for their health as adults. The example of tobacco use provides a simple, yet lucid, example of this point. The 434,000 deaths, 5 million years of potential life loss, and $\$ 68$ billion in health care costs annually attributable to tobacco result largely from American adults who began smoking as adolescents. ${ }^{1,19,22}$

In light of past research findings suggesting that religion positively affects adult health through its impact on health behaviors, research on religion and adolescent health behaviors, like tobacco use, is an area ripe for rigorous empirical research. Before turning to this task, however, we first review the epidemiology of religion among American youth.

\section{THE EPIDEMIOLOGY OF RELIGION AMONG AMERICAN YOUTH}

How widespread are religious beliefs and behaviors among American youth? Is religion important to them? Generally, American youth exhibit high levels of proreligious beliefs, attitudes, and behaviors. ${ }^{23}$ For example, $95 \%$ of American teens aged 13 to 17 believe in God (or a universal spirit), $76 \%$ believe that God observes their actions and rewards or punishes them, $93 \%$ believe that God loves them, $91 \%$ believe in heaven, $76 \%$ believe in hell, and $86 \%$ believe that Jesus Christ is God or the Son of God. Eighty percent of American teenagers say that religion is at least fairly important to them, and $40 \%$ report that they very much try to follow the teaching of their religion. Ninety-three percent report being affiliated with a religious group or denomination (59\% Protestant, 30\% Catholic, $1 \%$ some other Christian denomination, $2 \%$ Jewish, $1 \%$ some other affiliation). ${ }^{23}$

In addition to reporting relatively high levels of religious belief and affiliation, significant portions of the American youth population indicate that they regularly engage in religious practices. For example, $42 \%$ of teenagers report that they frequently pray alone, $48 \%$ report that they have attended church or synagogue within the past 7 days, and $36 \%$ report that they read the Bible weekly or more. Forty-one percent of American teens report that they are currently involved in Sunday School, 36\% report being involved with a church youth group, $23 \%$ are involved with church-sponsored activities to help the less fortunate, and $18 \%$ are involved in a church choir or music group. ${ }^{23}$

The sociodemographic distribution of religion reveals that (1) in general, adolescents' age does not appear to be strongly related to the importance that they ascribe to religion or to the likelihood that they are not affiliated with a religious denomination-age, however, does relate to attendance at religious services, with older adolescents attending less frequently than younger adolescents; (2) on average, females are slightly more religious than are males, as measured by the importance, attendance, and affiliation variables; (3) relative to white and Hispanic youth, black youth are more religious across all three religion indicators; (4) although adolescents from single- and two-parent families are equally likely to report that religion is very important to them, those in two-parent fami- 
lies attend religious services more often and are less likely to report that they are not religiously affiliated; (5) socioeconomic status is not strongly related to the importance that adolescents place on religion, but students with highly educated parents attend church more often and are less likely to say that they have no religious affiliation; (6) adolescents who live in nonurban areas report greater importance of religion and more frequent attendance at religious services than do adolescents from medium-size and large cities; and (7) relative to adolescents in other regions of the country, Southern youth attend church more often, are more likely to say that religion is very important to them, and are least likely to say that they do not belong to a religious group. ${ }^{6,12,13,24}$

Having established the behavioral risk factors that increase adolescent morbidity and mortality and having discussed the epidemiology of religion among American youth as a potential protective influence against these risk factors, we turn to the conceptual framework that guides the core empirical analysis of this research.

\section{A CONCEPTUAL FRAMEWORK ON RELIGION AND ADOLESCENT HEALTH}

The conceptual framework that guides this research derives from Wallace and William's socialization influence model. ${ }^{6}$ The model postulates that health-compromising and health-enhancing behaviors, and ultimately health outcomes, are the result of a dynamic socialization process that begins in childhood, extends through adolescence, and ultimately influences adult behavior, including behavior that affects morbidity and mortality. The model identifies the family as the adolescent's first and primary source of socialization into the norms and values of the larger society. The model hypothesizes that religion, a multidimensional construct that includes organizational (e.g., affiliation), behavioral (e.g., attendance), and attitudinal (e.g., importance) components, operates as a key secondary socialization influence that is integral to parents' belief systems and that assists them as they seek to inculcate their beliefs, values, and desired lifestyle patterns into their children. The model suggests that the variables typically used to measure adolescent religiosity - particularly denominational affiliation and religious attendance — are often, at least in part, under the control of parents and reflect to a large extent the types of doctrinal beliefs, information, education, and interpersonal influences to which parents want their children exposed.

The model hypothesizes that the impact of religion on adolescent morbidity and mortality is primarily indirect through a number of different mechanisms, or pathways. For example, religion can act as a source of social support, social control, individual and group identity, values, and, perhaps most important, as a key influence on health-related behaviors, which in turn relate to adolescent health outcomes and, ultimately, adult morbidity and mortality.

The hypothesized link between religion, health behaviors, and health outcomes results not simply through religion's constraining function, or what it proscribes, but also through what it encourages or prescribes. As noted by Northcutt and Jarvis, ${ }^{25}$

Religious prescriptions for healthy behavior might include encouragement to eat healthy, nutritious foods; the promotion of proper rest, exercise, and knowledge about bodily functions. On the other hand, proscriptions of unhealthy behaviors might include prohibitions against the use of tobacco, alcohol, and/or other harmful drugs, and the discouragement of 
immoderate activities such as promiscuous sex. Further, a religion which believes in the sanctity of the body may lead its members to avoid activities which have a high probability of injuring the body. (p. 813)

Because research on the relationship between religion and adolescent sickness and death is limited, empirical tests of the relationships hypothesized above are few. Nevertheless, two important health behaviors that have received some attention in past research-adolescent sexual involvement and drug use-lend support to the model's basic tenets that religion has a significant impact on adolescent health behavior in a fashion consistent with reducing adolescent and adult morbidity and mortality.

For example, research on religion and adolescent sex suggests that highly religious adolescents initiate sexual activity later, have fewer sexual partners, and engage in sex less often than their less religious peers. ${ }^{26-30}$ Accordingly, they are at less risk of experiencing the negative physical health problems associated with early sexual involvement. Similarly, research on adolescent drug use suggests that there is a moderate, yet significant, inverse relationship between religiosity and drug use. Young people who frequently attend religious services, who report that religion is important to them, and who are affiliated with religious denominations that explicitly prohibit drug use, on average, are less likely to be involved with drugs than are their less religiously engaged counterparts. ${ }^{6,12,13,24,31-36}$ Research on national trends in drug use suggests that religion may act not only as an individual-level phenomenon but also as a group-level protective factor against drug use. ${ }^{37}$ Based on their finding of significantly lower prevalences and minimal variation in drug use patterns among highly religious youth, relative to less religious youth, ${ }^{36}$ Bachman and Wallace observed that "America's drug epidemic occurred primarily among those not inoculated by religion" and that "highly religious youth were relatively immune to the plague which infected a significant portion of the nation's youth" (pp. 9-10).

In sum, the conceptual framework that guides this research posits that religion is an important secondary socialization influence that potentially affects adolescent morbidity and mortality through a variety of pathways, the most important of which is through its impact on adolescent health behaviors. To date, research relevant to this hypothesis has focused narrowly on selected behaviors, the most relevant for adolescent health being adolescents' precocious involvement in sex and their use of drugs. ${ }^{36,37}$ This article seeks to further test this hypothesis through the examination of a broader range of health behaviors than has been investigated before. Specifically, we use large, nationally representative samples of high school seniors to examine patterns and trends in the relationship between multiple religion measures and behaviors that can compromise adolescents' health (e.g., interpersonal violence, driving while drinking, drug use) and behaviors that can enhance their health (e.g., seat belt use, proper nutrition, exercise).

\section{METHOD}

\section{Sample}

Data for this sample are drawn from the University of Michigan's Monitoring the Future (MTF) project. The design and methods of the study are summarized briefly below; a more detailed description is available elsewhere. ${ }^{20,38}$ Each year, a three-stage national probability sample is drawn from the 48 coterminous states, and questionnaires 
are administered in approximately 135 high schools. ${ }^{39}$ First, particular geographic regions are selected; next, schools are selected; and finally, students are selected from within each school. This procedure has yielded nationally representative samples of 15,000 to 19,000 high school seniors annually since 1975 . Sample weights are assigned to each respondent to take into account school sample sizes, as well as variations in selection probabilities that occurred at earlier stages of the sampling procedures.

Students complete self-administered, machine-readable questionnaires during a normal class period. Overall questionnaire response rates average about $84 \%$. Absence on the day of data collection is the primary reason that students are missed; it is estimated that less than $1 \%$ of students refuse to complete the questionnaire. Six different questionnaire forms are used each year, each administered to a random one-sixth of the sample (prior to 1989, the MTF used only five forms). Items concerning substance use and sociodemographic measures appear in all forms. However, other items of interest in this study, such as unintentional and intentional injuries and lifestyle behavior items, appear in only one form; accordingly, analyses presented here are based on a random one-sixth of the total sample. Analyses of secular trends are based on data from 1976 to 1996. To ensure an adequate number of respondents, we combine data from 1995 and 1996, resulting in a sample of approximately 5,000 students. Given a sample of this size, there is the increased likelihood of findings that achieve statistical significance in the absence of being substantively significant. To reduce this likelihood, we generally highlight only those findings that exceed conventional standards for statistical significance (i.e., $p<.01$ ).

\section{Measures}

\section{Independent Variables}

Religion, properly understood, is a multidimensional construct. ${ }^{6,40-45}$ In this study, we consider its attitudinal, behavioral, and organizational dimensions. These dimensions are operationalized using measures of religious importance, attendance, and denominational affiliation, respectively. The specific wording of the religion measures and their associated response categories are as follows. Religious importance was measured with a single item: How important is religion in your life? Possible responses ranged from not important (1) to very important (4). Religious attendance was also measured with a single item: How often do you attend religious services? Possible responses ranged from never (1) to about once a week or more (4). Denominational affiliation is measured by the following question: What is your religious preference? Guided by the classification schemes of past research, ${ }^{46-50}$ respondents' denominational affiliation was coded into a four-category religious conservatism measure ranging from no affiliation (1) to conservative (4). The classification scheme of the affiliation measure is as follows: $1=$ none, $2=$ liberal (i.e., Episcopal, Presbyterian, United Church of Christ, Unitarian, Roman Catholic, Jewish), $3=$ moderate (i.e., Disciples of Christ, Lutheran, Methodist, Eastern Orthodox), and 4 = conservative (i.e., Baptist, Churches of Christ, Other Protestant, Other Religion, Latter Day Saints, Muslim/Moslem, Buddhist). The correlations between the religion measures are moderate to strong (see the appendix; $r=.60$ between attendance and importance, $r=.32$ between attendance and religious conservatism, and $r=.41$ between importance and conservatism).

Table 1 displays the univariate distributions of the religion measures. The data indicate that approximately half of America's high school seniors are at least somewhat religious, and a third of them can be thought of as being highly religious, with $32 \%$ reporting that 
Table 1. Levels of Religiosity Among American Youth, 1995-1996 Data Combined

\begin{tabular}{lc}
\hline & $\%$ \\
\hline Religious importance $(n=4,959)$ & \\
Not important & 14.4 \\
A little important & 25.0 \\
Pretty important & 28.5 \\
Very important & 32.1 \\
Religious attendance $(n=4,948)$ & \\
Never & 13.6 \\
Rarely & 36.3 \\
Once or twice a month & 17.0 \\
About once a week & 33.1 \\
Religious affiliation $(n=4,892)$ & \\
$\quad$ None & 15.9 \\
Liberal & 31.7 \\
Moderate & 11.4 \\
Conservative & 41.0 \\
\hline
\end{tabular}

religion is very important and 33\% indicating that they attend religious services at least once a week. Regarding denominational affiliation, a substantial minority of seniors belong to conservative denominations (41\%), approximately 1 in $10(11 \%)$ belong to moderate denominations, slightly less than a third belong to liberal denominations $(32 \%)$, and approximately $16 \%$ claim no religious affiliation.

\section{Dependent Variables}

The 11 specific health behaviors investigated here are grouped into three broad categories: unintentional and intentional injuries, substance use, and lifestyle behaviors. Table 2 presents the descriptive characteristics of the outcome measures. The specific wording of these measures is presented below.

Unintentional and Intentional Injury. We examined five measures of unintentional and intentional injury: (1) carrying a weapon (i.e., gun, knife, or club) to school, (2) engaging in interpersonal violence, (3) seat belt use, (4) drinking while driving, and (5) riding while drinking. Carrying a weapon was measured by a single item: During the past 4 weeks, on how many days (if any) were you carrying a weapon such as a gun, knife, or club to school? Possible responses ranged from none (1) to 10 or more times (6). Interpersonal violence was averaged by responses to three items concerning frequency of aggression toward others in the past 12 months $(\alpha=.77)$ : During the past 12 months, how often have you gotten into a serious fight in school or at work, taken part in a fight where a group of your friends were against another group, or hurt someone badly enough to need bandages or a doctor? Possible responses ranged from not at all (1) to five or more times (5). Respondents had to have at least two nonmissing responses to receive a valid index score. Frequency of seat belt use was measured by two items $(r=.87)$ : When you drive a car, how often do you wear a seat belt, and when you are riding in the front passenger seat of a 
Table 2. Means, Ranges, and Standard Deviations of Health Behavior Measures

\begin{tabular}{lcccc}
\hline Dependent Variable & Range & $M$ & $S D$ & $n$ \\
\hline Unintentional and intentional injury & & & & \\
$\quad$ Weapon & $(1-6)$ & 1.22 & .95 & 4,800 \\
$\quad$ Interpersonal violence & $(1-5)$ & 1.29 & .64 & 5,058 \\
Drive while drinking & $(1-6)$ & 1.23 & .69 & 4,156 \\
$\quad$ Ride while drinking & $(1-6)$ & 1.36 & .85 & 4,170 \\
$\quad$ Seat belt use & $(1-5)$ & 3.97 & 1.34 & 4,052 \\
Substance use & & & & \\
30-day cigarette & $(1-7)$ & 1.75 & 1.29 & 5,001 \\
Binge drinking & $(1-6)$ & 1.69 & 1.22 & 4,781 \\
$\quad$ Annual marijuana & $(1-7)$ & 2.14 & 1.95 & 4,931 \\
Lifestyle behaviors & & & & \\
$\quad$ Dietary & $(1-6)$ & 3.81 & 1.21 & 4,228 \\
Exercise & $(1-6)$ & 3.72 & 1.17 & 4,192 \\
$\quad$ Sleep & $(1-6)$ & 3.77 & 1.45 & 4,200 \\
\hline
\end{tabular}

car, how often do you wear a seat belt? Possible responses ranged from none (1) to always (5). Driving while drinking was measured by two items $(r=.76)$ : During the past 2 weeks, how many times (if any) have you driven a car, truck, or motorcycle after drinking alcohol and after having five or more drinks in a row? Possible responses ranged from none (1) to 10 or more times $(6)$. Riding while drinking was measured by two items $(r=.78)$ : During the past 2 weeks, how many times (if any) have you been a passenger in a car when the driver had been drinking and when you thought the driver had had five or more drinks? Possible responses ranged from none (1) to 10 or more times (6).

Substance Use. We used three single-item indicators of substance use: (1) current (i.e., past month) cigarette use, (2) binge drinking (i.e., five or more drinks in a row in the past 2 weeks), and (3) annual marijuana use. Current cigarette use was measured by the following item: How frequently have you smoked cigarettes during the past 30 days? Possible responses ranged from not at all (1) to two packs or more per day (7). Binge drinking was measured by the following question: In the past 2 weeks, how many times have you had five or more drinks in a row? Possible responses ranged from none (1) to 10 or more times (6). Annual marijuana use was measured by the following item: On how many occasions (if any) have you used marijuana during the past 12 months? Possible responses ranged from none (1) to 40 or more times (7). These are standard self-report measures of substance use, and prior research supports their validity. ${ }^{51,52}$

Lifestyle Behaviors. The three lifestyle variables focused on adolescent (1) dietary habits, (2) exercise, and (3) sleep patterns. The dietary habits index averages responses to three items concerning how often students eat breakfast, green vegetables, and fruit ( $\alpha=.74$ ). Possible responses ranged from never (1) to everyday (6). Respondents had to have at least two nonmissing responses to receive a valid score on the index. Frequency of exercise was measured by two items $(r=.63)$ : How often do you exercise vigorously, and how often do you actively participate in sports, athletics, or exercising? Possible responses ranged from never (1) to everyday (6). Sleep was measured by a single item: How 
often do you get at least 7 hours of sleep? Possible responses ranged from never (1) to everyday (6).

\section{Research Questions and Analysis Strategy}

Young people who carry weapons, fight, drive while drinking, ride with others who have been drinking, use drugs, and do not regularly wear seat belts are at elevated risk for a variety of negative health consequences, including, but not limited to, motor vehicle crashes and being perpetrators and/or victims of physical violence. Young people who do not eat properly, who do not exercise regularly, and who fail to get adequate rest initiate a lifestyle pattern that increases their risk for a variety of negative health consequences as adults, including heart disease, cancer, and stroke. The general question that motivates this research is the following: Are religiously oriented young people less likely than other youth to participate in behaviors that compromise their health and more likely than other youth to engage in health-enhancing behaviors?

To address these two interrelated issues, we first estimated a series of one-way analysis of variance (ANOVA) models in which the religion measures were treated as independent variables and the 11 health behaviors were treated as dependent variables. Next, we examined whether the relationship between the religion measures and the health outcomes were explainable in terms of other key sociodemographic factors. Specifically, we compared the ANOVA results described above with ANOVA results in which the relationships between religion and the health behaviors were estimated while controlling for the effects of sociodemographic factors. Finally, we explored the extent to which trends ir the health behaviors differed from 1976 to 1996, depending on students' level of "religiosity" (an index that combines the importance and attendance measures).

\section{RESULTS}

Are religious youth less likely than other youth to engage in behaviors that are potentially detrimental to their health and more likely than other youth to engage in behaviors that can enhance their health? In general, the answer to both of these questions is yes. Results for specific health behaviors are described below.

\section{Unintentional and Intentional Injuries}

The ANOVA results presented in the first five rows of Table 3 indicate that religious importance and attendance relate significantly $(p<.01)$ and positively to wearing seat belts and negatively to involvement in interpersonal violence, driving after drinking, and riding with someone under the influence of alcohol. Post hoc comparisons tests reveal that young people who are most religious (i.e., for whom religion is very important and who attend church weekly or more) are significantly $(p<.05)$ different from their peers in their involvement in the injury-related behaviors.

The relationship between the third religion measure-denominational affiliationand the injury-related behaviors is more complex. For example, students belonging to liberal denominations are significantly $(p<.05)$ less likely to have carried a weapon than students with no religious affiliation and students who belong to a conservative denomination; seniors who are affiliated with liberal and moderate denominations are more 


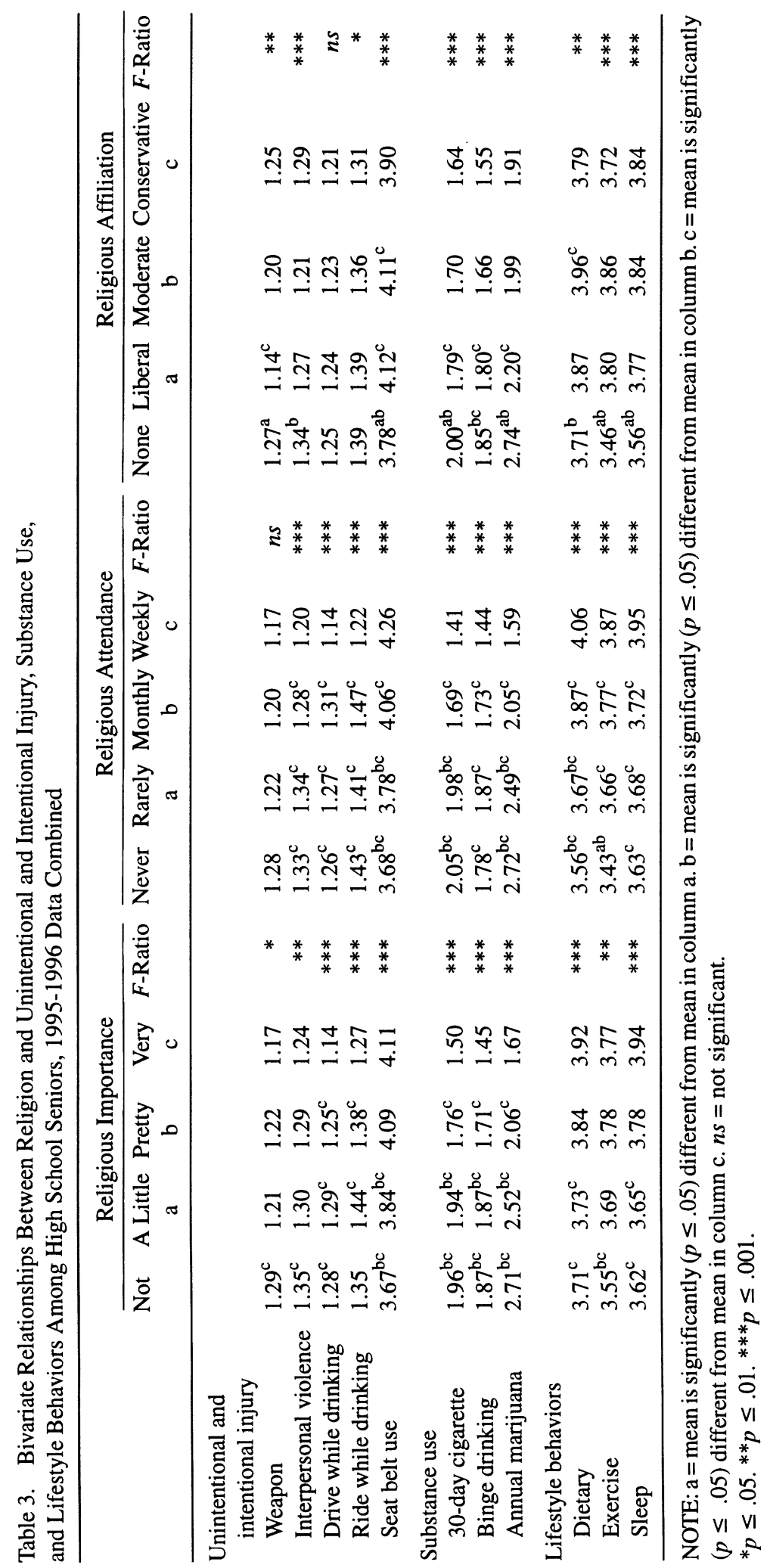




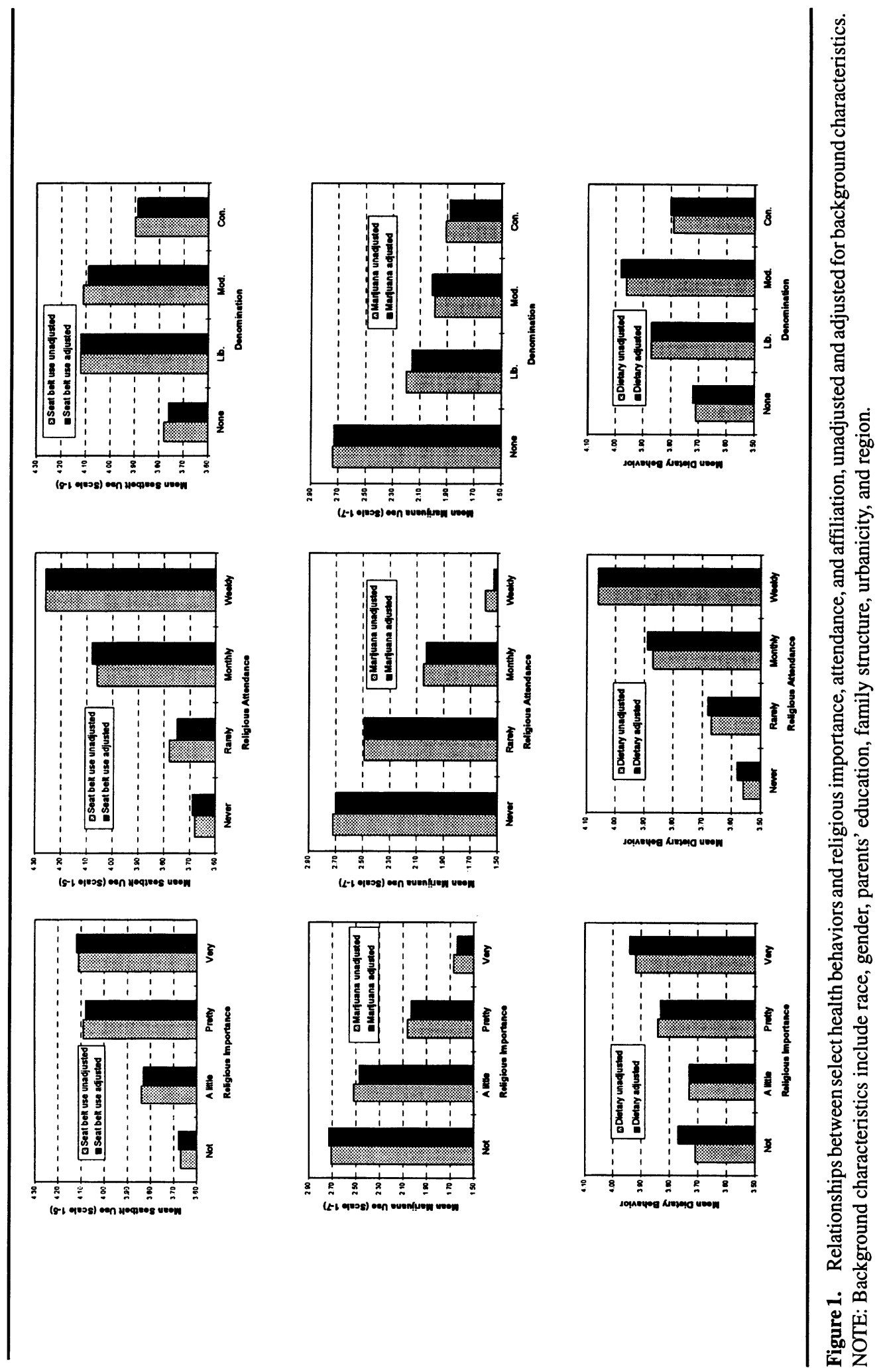


likely than those with no affiliation and those with conservative affiliations to use seat belts.

Multivariate ANOVA models in which sociodemographic factors were controlled suggest that they have relatively little impact on the relationship between religion and the injury-related behaviors (see Figure 1, the first row of charts). (Because of space considerations, data for only one of the injury-related health outcomes-seat belt use-are presented, but the same general pattern holds across the range of outcomes.) This point is illustrated by the fact that even after adjusting for the sociodemographic factors, there is virtually no change in seniors' mean levels of seat belt use across categories of the religious importance, attendance, or denominational affiliation measures.

\section{Substance Use}

Cigarette use, heavy episodic (i.e., binge) drinking, and marijuana use are all related to short-term as well as long-term health problems, physical and psychological addiction, and elevated risk for premature death. While most religious groups discourage the use of tobacco and heavy alcohol use, virtually all are against the use of marijuana (and other drugs) by virtue of their illegal status. Accordingly, it was expected that the religion measures would relate negatively to each of the drug use measures. In line with this expectation, the data in Table 3 (and Figure 1) reveal relatively clear linear relationships between all three religion measures and all three categories of drugs, with the mean levels of current cigarette use, binge drinking in the past 2 weeks, and annual marijuana use being lowest among those young people for whom religion is most important, who attend church once a week or more, and who belong to a conservative religious denomination. Comparison of the simple one-way ANOVA models with the multivariate ANOVA models indicates that these findings hold true, even after controlling for sociodemographic factors (see Figure 1, second row of graphs).

\section{Lifestyle Behaviors}

Dietary factors and physical activity patterns are the second leading cause of mortality among Americans, accounting for at least 300,000 deaths annually. ${ }^{1}$ Many of the dietary and activity patterns that are developed during adolescence continue into adulthood. Accordingly, adolescent diet, exercise, and rest patterns are important to investigate as precursors to adult behaviors predictive of adult morbidity and mortality. The data presented in Table 3 suggest that religion promotes healthy lifestyle behaviors. More specifically, the data indicate that young people for whom religion is very important and who attend church weekly are significantly more likely than their less religious peers to eat in a healthy fashion, to exercise regularly, and to get adequate sleep.

The denominational affiliation data indicate that lifestyle behaviors are generally highest among seniors affiliated with liberal and moderate denominations, somewhat lower among members of conservative denominations, and lowest among young people who are not affiliated with any religious denomination. Interestingly, controlling for sociodemographic factors does seem to improve the mean level of healthy dietary behavior among youth for whom religion is not important; however, the increase only improves their position relative to seniors who indicate that religion is "a little important," not those for whom religion is "pretty important" or for whom religion is "very important." Data on the relationships between attendance and lifestyle behaviors, as well as affiliation and 
lifestyle behaviors, do not show any substantial impact of controlling for sociodemographic factors (see Figure 1, third row of graphs).

\section{Trends}

Figure 2 graphically presents trends in the injury, substance use, and lifestyle health behavior measures. The data on adolescent injury-related behavior indicate that with the exception of seat belt use, there has been very little change in seniors' self-reported involvement in interpersonal violence, weapons possession, or riding in or driving a vehicle after they or another person had been drinking. Over time, seniors' seat belt use has risen, probably as a result of mandatory seat belt laws that have been enacted across the country. Trends in seniors' level of drug use have varied over time, depending on the specific drug in question. For example, while levels of cigarette use have been relatively stable since the early 1980 s, levels of alcohol use have generally declined over this same time period, and marijuana use has peaked, declined, and begun to rise again. Seniors' involvement in each of the three lifestyle behaviors has decreased over time, with this decline being greatest for sleep, somewhat lower for dietary behaviors, and lowest for exercise.

To what extent has religion promoted seniors' physical well-being over time and protected them from involvement in behaviors that are detrimental to their health? To address this question, we combined the religious importance and religious attendance measures to create a religiosity index; we then plotted seniors' mean values for selected health behaviors by their level of religiosity. The results of these analyses are presented in Figure 3.

The top graph in Figure 3 indicates that highly religious seniors have been more likely than other seniors to have used seat belts over time, and this overall pattern has actually increased from the mid-1980s to the present. The middle graph shows the relationship between seniors' religiosity and their level of marijuana use from 1976 to 1996 . Consistent with Bachman and colleagues' earlier research, ${ }^{36,37}$ these data indicate that highly religious seniors have been relatively unaffected by the broad societal-level changes in marijuana use; their use has remained relatively low irrespective of the behaviors of the rest of the population. The final graph in Figure 3 presents the relationship between seniors' level of religiosity and their dietary behavior. The data reveal that although there has been a decrease in the levels of proper dietary behavior among all seniors, those with high and medium-high levels of religiosity have been, and continue to be, more likely to eat properly than those with medium-low and low levels of religiosity.

\section{DISCUSSION}

Although there is a large and growing body of research on religion and adult health, to our knowledge, the present research is one of the first studies to empirically investigate the relationship between religion and a broad range of health behaviors among adolescents. Extant research that does explore the relationship between religion and adolescent health typically uses small nonrepresentative samples, poorly measures religion, and only emphasizes religion's role as a constraint against delinquent behavior (e.g., precocious sex and drug use). In an attempt to address some of these limitations, this study used large, nationally representative samples, multiple measures of religion, and a broad conceptual framework hypothesizing that religion does not only simply constrain behavior, 

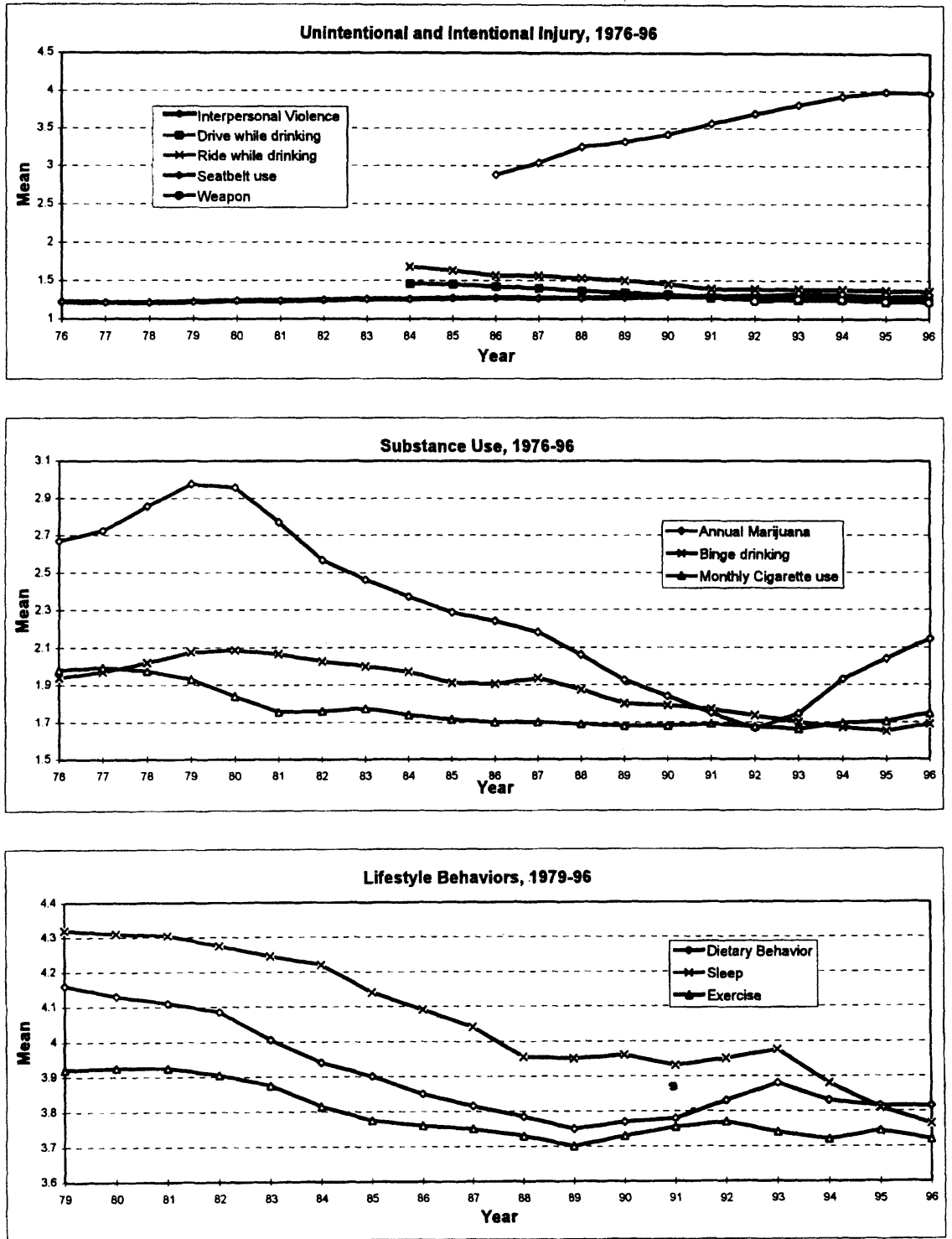

Figure 2. Trends in health behaviors among high school seniors, 1976-1996.

but it also encourages or promotes adolescents' involvement in behavior that can protect or enhance their health.

The relationships between religion and health behaviors are weak to moderate (see the appendix). Nevertheless, the results of this study are generally consistent with the conceptual framework. On average, seniors who attend church weekly and report that religion is important are less likely than other youth to engage in high-risk behaviors and are more likely to engage in behaviors that promote long-term physical well-being. However, the relationships between religious conservatism and involvement in health behaviors, other than substance use, did not demonstrate a consistent pattern (see Table 3). 

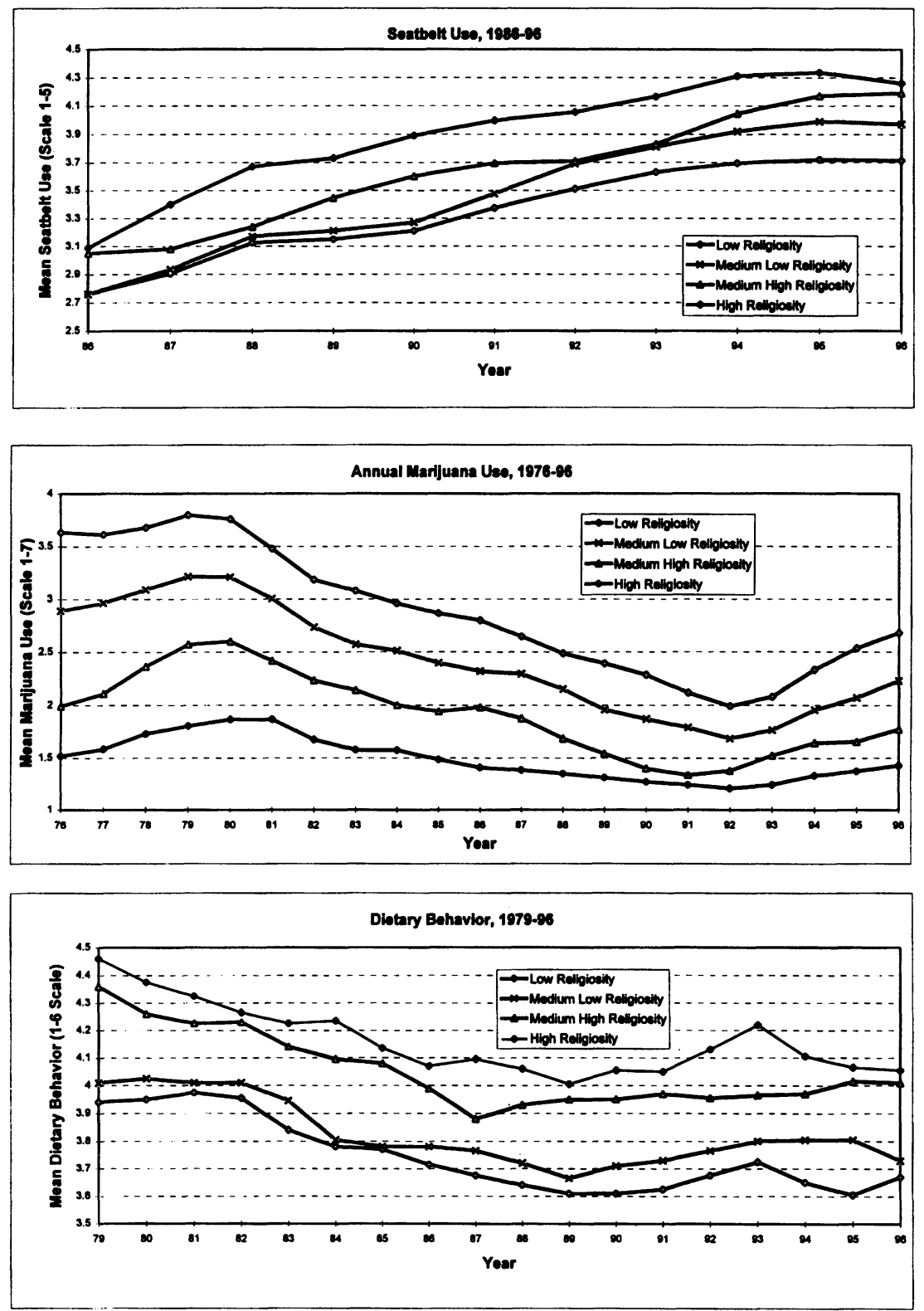

Figure 3. Trends in select health behaviors by religiosity among high school seniors, 1976-1996.

Although the findings of this study generally support the religion component of Wallace and William's ${ }^{6}$ socialization influence model, the specific mechanisms through which religious attendance, importance, and denominational affiliation relate to various adolescent health outcomes have yet to be determined. Furthermore, it is not clear that these mechanisms are necessarily unique to religion per se. For example, in addition to religion, Wallace and Williams emphasize the importance of peers, school, community, and other 
more macrolevel contexts as additional secondary socialization influences on adolescents' health behaviors. To the extent that these other socialization influences encourage attitudes and beliefs that discourage risk behaviors and encourage health-enhancing behaviors, the importance of religion may be reduced. However, it should be noted that past research that controlled for various school, peer, and other lifestyle factors suggests that religion is still an important correlate of adolescent health outcomes. ${ }^{53}$

Religion is only one of many important variables that relate to adolescent health behaviors; nevertheless, its continued importance as a correlate of adolescent health behavior, even after other factors are controlled, suggests that it is a factor that future research should not ignore. Rather, future research should seek to further specify the mechanisms through which religion relates to adolescent health and the ways in which it may act independent of, in concert with, or in competition against other factors. While this study, guided by Wallace and William's ${ }^{6}$ socialization influence model, posits that religion influences adolescent health behaviors, future research should consider the possibility that adolescent health behaviors influence religion. For example, in a longitudinal study of late adolescents, Thornton and Camburn ${ }^{29}$ found that having positive attitudes toward premarital sex reduced adolescents' attendance at religious services.

Although this study has identified positive relationships between religious attitudes, religious practices, and health behaviors, it is not clear that other aspects of religion are not important, nor is it clear that these other aspects of religion may not negatively affect adolescent health. For example, to the extent that there is a mismatch between young people's personal religious orientation and that of their parents, religion may actually serve as a risk factor for a variety of negative health outcomes. Similarly, the teachings of some religious denominations or sects may expect, if not require, that their adherents not pursue medical treatment, not maintain prescribed health regimens, and not engage in practices that can, at least potentially, protect health (e.g., condom use among those who choose to be sexually active).

\section{CONCLUSION}

The fact that churches, synagogues, and mosques have regular access to adolescents, their families, and their peers suggests that religious institutions are a potentially important, albeit often ignored, ally in the nation's efforts to promote the health of the youth of today and the adults of tomorrow. In light of the very real risks that negatively impinge on the health of many American young people, health practitioners, social workers, clergy, youth service providers, parents, and others concerned about adolescents' health must explore ways in which to work collaboratively to promote the holistic mental, physical, and spiritual well-being of America's youth. As public health, social work, medicine, and other helping professions seek to better meet the needs of young people through direct practice, research, and education, they should begin to explore beyond their traditional boundaries and pursue the untapped potential that lies in partnerships with religious professionals and religious institutions. 


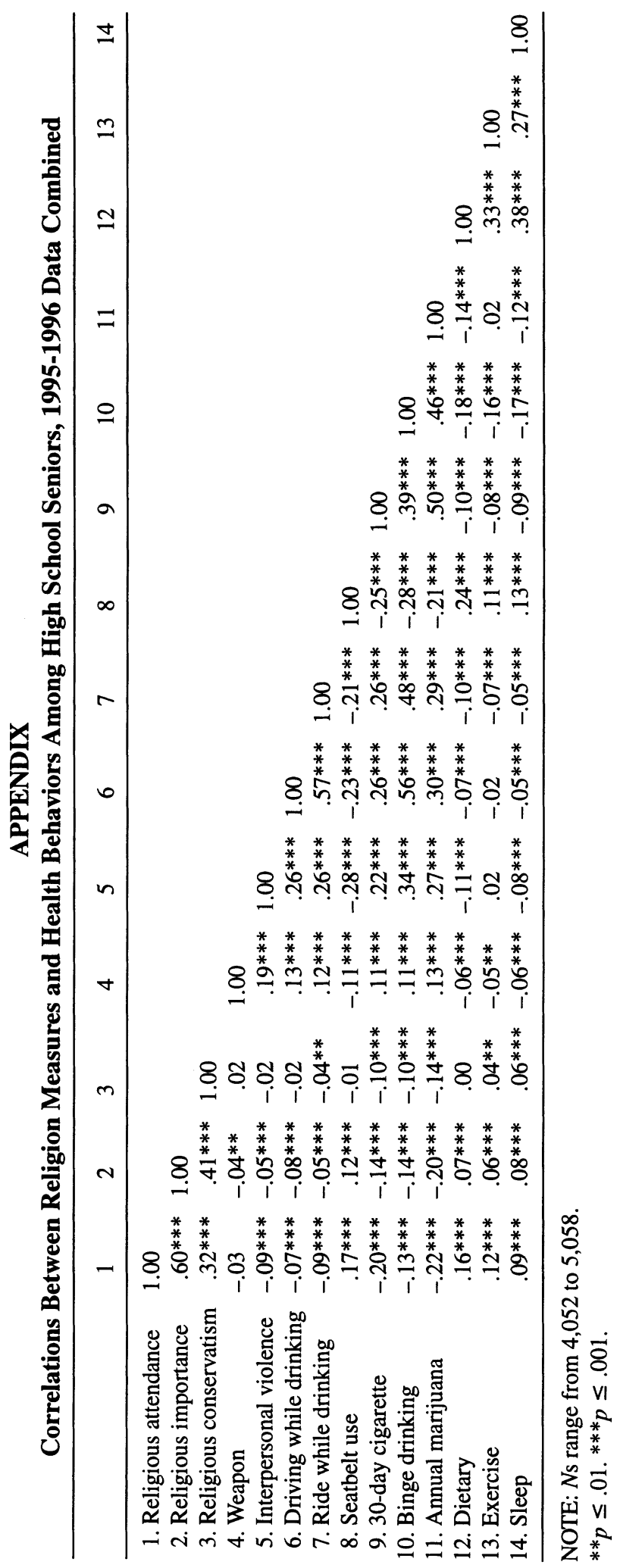




\section{References}

1. McGinnis JM, Foege WH: Actual causes of death in the United States. JAMA 270:55-60, 1993.

2. Levin JS: Religion and health: Is there an association, it is valid, and it is causal? Soc Sci Med 38:1475-1482, 1994.

3. Levin JS, Vanderpool HY: Religious Factors in Physical Health and the Prevention of Illness. New York, Haworth, 1992.

4. Levin JS, Vanderpool HY: Is frequent religious attendance really conducive to better health? Toward an epidemiology of religion. Soc Sci Med 24:589-600, 1987.

5. Levin JS, Schiller PS: Is there a religious factor in health? J Religion Health 26:9-36, 1987.

6. Wallace JM Jr, Williams DR: Religion and adolescent health-compromising behavior, in Schulenberg J, Maggs JL, Hurrelmann K (eds.): Health Risks and Developmental Transitions During Adolescence. Cambridge, Cambridge University Press, 1997, pp. 444-468.

7. Office of Technology Assessment (OTA): Adolescent Health: Vol. 2. Background and the Effectiveness of Selected Prevention and Treatment Services (OTA-H-466). Washington, DC, Government Printing Office, 1991.

8. Diclemente RJ, William BH, Ponton LE: Handbook of Adolescent Health Risk Behavior. New York, Plenum Press, 1996.

9. Hawkins JD, Catalano RF, Miller JY: Risk and protective factors for alcohol and other drug problems in adolescence and early adulthood: Implications for prevention. Psychol Bull 112:64-105, 1992.

10. Dryfoos JG: Adolescents at Risk: Prevalence and Prevention. New York, Oxford University Press, 1990.

11. Rohrbaugh J, Jessor R: Religiosity in youth: A control against deviant behavior. J Pers 43:136-155, 1975.

12. Benson PL, Donahue MJ, Erickson JA: Adolescence and religion: A review of the literature from 1970 to 1986. Res Soc Scientific Study Religion 1:153-181, 1989.

13. Donahue MJ, Benson PL: Religion and the well-being of adolescents. J Soc Issues 51:145-160, 1995.

14. Hyde KE: Religion in Childhood and Adolescence: A Comprehensive Review of the Research. Birmingham, AL, Religious Education Press, 1990.

15. Centers for Disease Control and Prevention: Leading causes of mortality and morbidity and contributing behaviors in the United States [On-line]. Available at http://www.cdc.gov/ nccdphp/dash/ahsumm/ussumm.htm, 1997, pp. 1-2.

16. Leschoier I, Gallagher SS: Unintentional injury, in Diclemente RJ, William BH, Ponton LE (eds.): Handbook of Adolescent Health Risk Behavior. New York, Plenum Press, 1996, pp. 225-258.

17. Sells CW, Blum RW: Current trends in adolescent health, in Diclemente RJ, William BH, Ponton LE (eds.): Handbook of Adolescent Health Risk Behavior. New York, Plenum Press, 1996, pp. 5-34.

18. Diclemente RJ, William BH, Ponton LE: Adolescents at risk: A generation in jeopardy, in Diclemente RJ, William BH, Ponton LE (eds.): Handbook of Adolescent Health Risk Behavior. New York, Plenum Press, 1996, pp. 1-4.

19. Preventing Tobacco Use Among Young People: A Report of the Surgeon General (DHHS Pub. No. S/N 017-001-0049-0). Atlanta, GA, U.S. Department of Health and Human Services, Public Health Service, 1994.

20. Johnston LD, O'Malley PM, Bachman JG: National Survey Results on Drug Use From the Monitoring the Future Study, 1975-1995: Vol. 1. Secondary School Students (NIH Pub. No. 97-4139). Rockville, MD, National Institute on Drug Abuse, 1996.

21. Kann L, Anderson JE, Holtzman D, Ross J, Truman BI, Collins JJ, Kolbe LJ: HIV-related knowledge, beliefs, and behaviors among high school students in the United States: Results from a national survey. J School Health 61:397-401, 1991. 
22. Cigarette smoking attributable mortality and years of potential life lost-United States, 1990. MMWR 42:645-664, 1993.

23. Gallup GH Jr, Bezilla R: The Religious Life of Young Americans. Princeton, NJ, George H. Gallup International Institute, 1992.

24. Bahr SJ, Hawks RD: Religious organizations, in Coombs RH, Ziedonis D (eds.): Handbook on Drug Abuse Prevention. Boston, Allyn \& Bacon, 1995, pp. 159-179.

25. Northcutt HC, Jarvis GK: Religion and differences in morbidity and mortality. Soc Sci Med 25:813-824, 1987.

26. Hayes C (ed.): Risking the Future: Adolescent Sexuality, Pregnancy, and Childbearing (Vol. 1). Washington, DC, National Academy Press, 1987.

27. Miller BC, Moore KA: Adolescent sexual behavior, pregnancy, and parenting: Research through the 1980s. J Marriage Fam 52:1025-1044, 1990.

28. Murry V: Black adolescent females: A comparison of early versus late coital initiators. Fam Relations 43:342-348, 1994.

29. Thornton A, Camburn D: Religious participation and adolescent sexual behavior and attitudes. J Marriage Fam 51:641-653, 1989.

30. Zelnick MK, Ford K: Sex and Pregnancy in Adolescence. Beverly Hills, CA, Sage, 1981.

31. Amey CH, Albrecht SL, Miller MK: Racial differences in adolescent drug use: The impact of religion. Substance Use \& Misuse 31:1311-1332, 1996.

32. Burkett SR: Religiosity, beliefs, normative standards and adolescent drinking. J Stud Alcohol 41:662-671, 1980.

33. Cochran JK: The effects of religiosity on adolescent self-reported frequency of drug and alcohol use. J Drug Issues 22:91-104, 1992.

34. Hadaway CK, Elifson KW, Petersen DM: Religious involvement and drug use among urban adolescents. J Soc Scientific Study Religion 23:109-128, 1984.

35. Kandel DB: Drug and drinking behavior among youth. Ann Rev Soc 6:235-285, 1980.

36. Bachman JG, Wallace JM Jr: Religion and drug use, in Clayton R (ed.): Encyclopedia of Drugs and Alcohol. Unpublished manuscript.

37. Bachman JG, Johnston LD, O'Malley PM, Humphrey RH: Explaining the recent decline in marijuana use: Differentiating the effects of perceived risks, disapproval, and general lifestyle factors. J Health Soc Behav 29:92-112, 1988.

38. Bachman JG, Johnston LD, O'Malley PM: The Monitoring the Future Project After TwentyTwo Years: Design and Procedures (Monitoring the Future Occasional Paper 38). Ann Arbor, MI: Institute for Social Research, 1996.

39. Kish L: Survey Sampling. New York: John Wiley, 1965.

40. Chatters LM, Levin JS, Taylor RJ: Antecedents and dimensions of religious involvement among older Black adults. J Gerontol: Soc Sci 47:S269-S278, 1992.

41. Cornwall M, Albrecht S, Pitcher B, Cunningham P: The dimensions of religiosity: A conceptual model and empirical test. Rev Religious Res 27:226-244, 1986.

42. Ellison CG, Taylor RJ: Turning to prayer: Social and situational antecedents of religious coping among African Americans. Rev Religious Res 38:111-131, 1996.

43. Levin JS, Chatters LM, Taylor RJ: Religious effects on health status and life satisfaction among black Americans. J Gerontol: Soc Sci 50B:S154-S163, 1995.

44. Levin JS, Taylor RJ, Chatters LM: A multidimensional measurement model of religiosity in black Americans. Sociological Q 36:157-173, 1995.

45. Williams DR: The measurement of religion in epidemiologic studies, in Levin JS (ed.): Religion in Aging and Health: Theoretical Foundations and Methodological Frontiers. Thousand Oaks, CA, Sage, 1994, pp. 125-148.

46. Iannaccone LR: Why strict churches are strong. Am J Soc 99:1180-1211, 1994.

47. Lorch B, Hughes RH: Religion and youth substance use. J Religion Health 24:197-208, 1985.

48. Olson JK: Crime and religion: A denominational and community analysis. J Sci Study Religion 29:395-403, 1990. 
49. Roof WC, McKinney W: American Mainline Religion. New Brunswick, NJ: Rutgers University Press, 1987.

50. Smith TW: Classifying Protestant denominations. Rev Religious Res 31:225-245, 1990.

51. Johnston LD, O'Malley PM: Issues of validity and population coverage in student surveys of drug use, in Rouse BA, Kozel NJ, Richards LG (eds.): Self-Report Methods of Estimating Drug Use (NIDA Research Monograph 57, Pub. No. [ADM] 87-1535). Washington, DC, Department of Health and Human Services, 1985, pp. 31-54.

52. Wallace JM Jr, Bachman JG: Validity of self-reports in student based studies on minority populations: Issues and concerns, in De La Rosa MR, Adrados JR (eds.): Drug Abuse Among Minority Youth: Advances in Research and Methodology (NIDA Research Monograph 130). Rockville, MD, National Institute on Drug Abuse, 1993, pp. 167-200.

53. Wallace JM Jr, Bachman JG: Explaining racial/ethnic differences in drug use: The impact of background and lifestyle. Soc Prob 38:333-357, 1991. 